\title{
Determination of Adulterants in Diesel by Multivariate Calibration Associated With LED Spectrofluorimetry
}

\author{
Marilena Meira ${ }^{1}$, Cristina M. Quintella ${ }^{2}$, Erika M. de O. Ribeiro ${ }^{2}$, Alexandre K. Guimarães ${ }^{2} \&$ \\ Weidson Leal Silva ${ }^{2}$ \\ ${ }^{1}$ Instituto Federal de Educação, Ciência e Tecnologia da Bahia, Campus Simões Filho, BA, Brazil \\ ${ }^{2}$ Instituto de Química, Universidade Federal da Bahia, Campus de Ondina, Salvador, BA, Brazil \\ Correspondence: Marilena Meira, Instituto Federal de Educação, Ciência e Tecnologia da Bahia, Campus Simões \\ Filho, CEP: 43.700-000, BA, Brazil. E-mail: marilenameira@gmail.com
}

Received: June 17, 2014 Accepted: September 11, 2014 Online Published: October 20, 2014

doi:10.5539/ijc.v6n4p24 URL: http://dx.doi.org/10.5539/ijc.v6n4p24

\begin{abstract}
In this paper, multivariate calibration models have been developed for determination of common adulterants (kerosene, turpentine and residual oil from fried foods) added to diesel. The samples were analyzed by LED spectrofluorimetry and the multivariate calibration models were developed by Partial Least Squares (PLS). The proposal is suggested as an analytical methodology of low-cost, fast and non-destructive able to quantify the presence of contaminants in the diesel. The results showed that adulterants concentrations were adequately reproduced by the fluorescence spectral data.
\end{abstract}

Keywords: adulteration, diesel, PLS, spectrofluorimetry

\section{Introduction}

The intentional addition of adulterants to diesel has a negative effect on fuel properties and on the engine performance, such as fuel consumption, engine start-up control and engine heating. In addition, adulteration of fuel increases the emission of exhaust gases, hydrocarbons and particulate material (Corgozinho, Pasa, \& Barbeira, 2008).

Several analytical methodologies have been developed for identification or quantification of adulterants in diesel and biodiesel-diesel blends in recent years. Patra and Mishra developed a method for detected contamination in diesel by excitation-emission matrix spectral subtraction fluorescence (Patra \& Mishra, 2002). Corgozinho et al. related a method for quantifying of residual vegetable oil in diesel oil using synchronous spectrofluorimetry and PLS (Corgozinho, Pasa, \& Barbeira, 2008). Oliveira et al. reported a method to determine adulteration of diesel/biodiesel blends by vegetable oil using Fourier transform (FT) near infrared spectrometry and FT-Raman spectroscopy (Oliveira, Brandão, Ramalho, Costa, Suarez, \& Rubim, 2007). Vasconcelos et al. using near-infrared overtone regions determined biodiesel content and adulteration of diesel/biodiesel blends with vegetable oils (Vasconcelos, Souza Jr., Pimentel, Pontes, \& Pereira, 2012). Pontes et al. detected adulteration in diesel/biodiesel blends using a method based near infrared spectrometry and multivariate classification (Pontes, Pereira, Pimentel, Vasconcelos, \& Silva, 2011). Gaydou et al. detected vegetable oil as an adulterant in diesel/biodiesel blends associating NIR/MIR PLS (Gaydou, Kister, \& Dupuy, 2011). Roy developed a fiber-optic sensor for determining kerosene as an adulterant in petrol and diesel (Roy, 1999). Souza et al. determined adulteration of Brazilian S-10 diesel by lubricant oil using MIR spectroscopy and PLS (Souza, Mitsutake, Gontijo, \& Borges Neto, 2014). Brandão et al. used high performance liquid chromatography and multivariate methods to determine adulteration of diesel by vegetable oils and fats (Brandão, Braga, \& Suarez, 2012).

In a previous work, our team developed a method and a sensor for monitoring quality in processes for obtaining fuels using spectrofluorimetry and Principal Component Analysis (PCA) (Quintella, Guimarães, \& Musse, 2009). Also we reported a method for identification of the adulteration to diesel by the addition of residual cooking oil using spectrofluorimetry total 3D and PCA (Meira et al., 2011) and a spectrofluorimeter was patented (Quintella et al., 2011). This present study focuses on the quantification of adulterants added to diesel (kerosene, turpentine and residual oil from fried foods) by high-power light-emitting diode (LED) spectroluorimetry and partial least squares (PLS) regression. LEDs have the following advantages as alternatives sources of excitation in 
spectrofluorimetry: They are near monochromatic, have low cost, produce very little heat, have no coherence problems, have extended life, are small and can easily be modulated (Young, Garini, Dietrich, van Oel, \& Liqui Lung, 2004).

\section{Materials and Methods}

Standard of diesel was supplied by Petrobras-Brazil and the mixtures of diesel with adulterants (kerosene, turpentine and residual oil from fried foods) were prepared at concentrations of 0 to $100 \%$. Diesel neat and mixtures were analyzed in a LED Fluorescence Spectrometer of Quimis Q-798FIL. These standards were analyzed in duplicate without any prior treatment being used the natural fluorescence of fluids, with quartz cuvettes of $1 \mathrm{~cm}$. The standards were excited with violet LED and emission was detected from 335-1000 nm at intervals of $0.38 \mathrm{~nm}$ in LED spectrofluorimeter.

To assess the applicability of the fluorescence method for quantifying the adulterants content multivariate calibration models were developed by Partial Least Squares (PLS) using the software Unscrambler X 10.0.1. Through the PLS models fluorescence spectra are correlated with the corresponding values of the concentration of each adulterant. Each PLS was developed using mean centered fluorescence spectra as independent variables and the concentration values as dependent variables. In calibration step of each PLS, the relationship between spectra and concentration values was estimated from a set of reference samples, and in the validation step the results of the calibration were used to estimate the concentrations from samples that were not used in the calibration step. In this case, mixtures of diesel with adulterant (kerosene, turpentine or residual oil from fried foods).

\section{Results and Discussion}

\subsection{Calibration of the PLS models}

Table 1 shows the mixtures of each adulterant added to diesel (kerosene, turpentine and residual oil from fried foods) analyzed by LED spectroluorimetry and used in the construction of the multivariate calibration models that were developed by partial least squares (PLS) regression using the entire spectral and the entire calibration set described in Table 1. The PLS models were built using the whole fluorescent spectra as independent variables and the values of the concentrations of each adulterant in diesel as dependent variables (Table 1).

Table 1. Concentration of adulterant added to diesel used in the construction of the PLS models

\begin{tabular}{ccc}
\hline Kerosene (\%) & Turpentine (\%) & Residual oil from fried foods (\%) \\
\hline 0 & 0 & 0 \\
2 & 2 & 2 \\
4 & 4 & 4 \\
6 & 6 & 6 \\
8 & 8 & 8 \\
10 & 10 & 10 \\
20 & 20 & 20 \\
30 & 30 & 30 \\
40 & 40 & 40 \\
50 & 50 & 50 \\
60 & 60 & 60 \\
70 & 70 & 70 \\
80 & 80 & 80 \\
90 & 90 & 90 \\
100 & 100 & 100 \\
\hline
\end{tabular}

Figures 1 and 2 present respectively fluorescence spectra and PLS for the mixtures of kerosene in diesel. The 
coefficient of correlation of the curve presented near to $1(0.9969)$ and $\mathrm{R}^{2}$ of 0.99818 indicate the strength of the association between the two variables and the efficiency of the PLS to carry out the predictions. Figure 3 presents that two latent variables predicted $100 \%$ of the total variance (almost $100 \%$ for the first latent variable). Therefore, the model was proved useful to predict changes in concentration of turpentine added to diesel based on the fluorescence spectral variance.

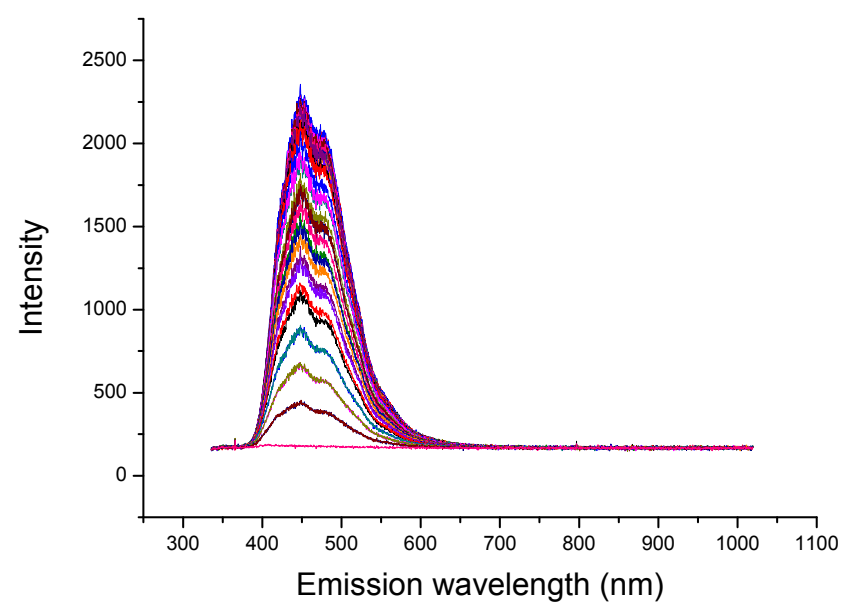

Figure 1. Fluorescence espectra of mixtures of kerosene in diesel (0-100\%)

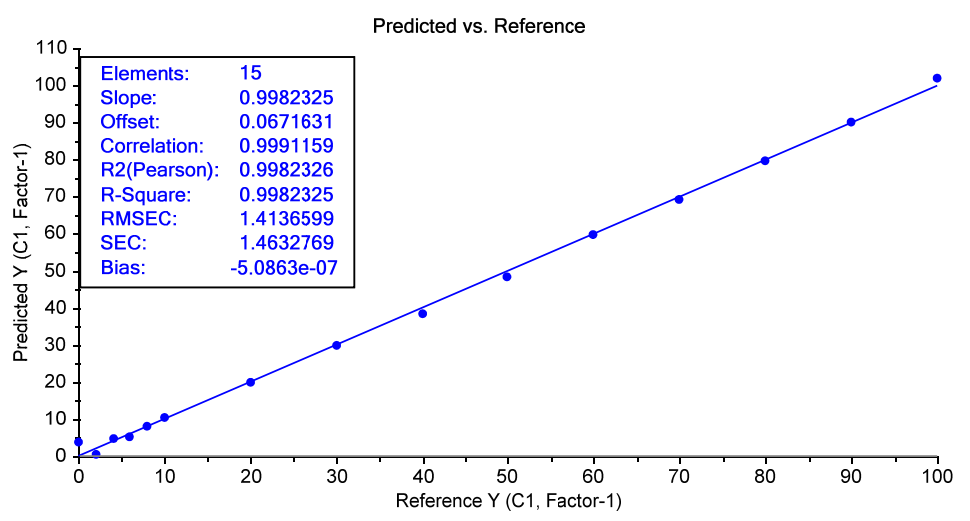

Figure 2. PLS model de mixtures of kerosene added to diesel

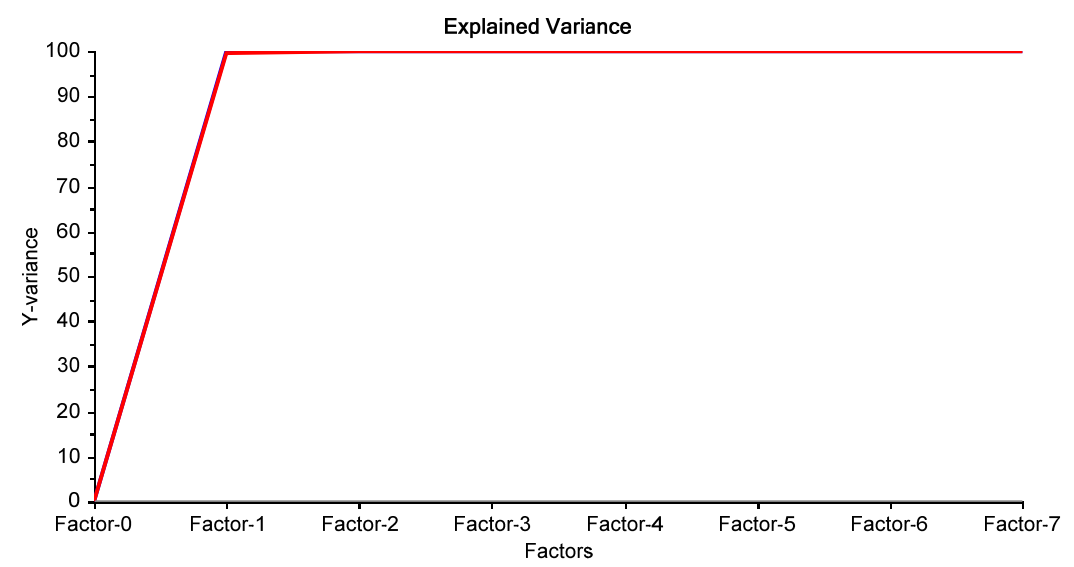

Figure 3. Explained variance of the PLS model de mixtures of kerosene added to diesel 
Figures 4 and 5 present respectively fluorescence spectra and PLS for the mixtures of turpentine in diesel. The coefficient of correlation of the curve presented near to $1(0.9991)$ and $R^{2}$ of 0.9982 indicate the strength of the association of the two variables and the efficiency of the PLS to carry out the predictions. Only two latent variables predicted almost $100 \%$ of the total variance (Figure 6).

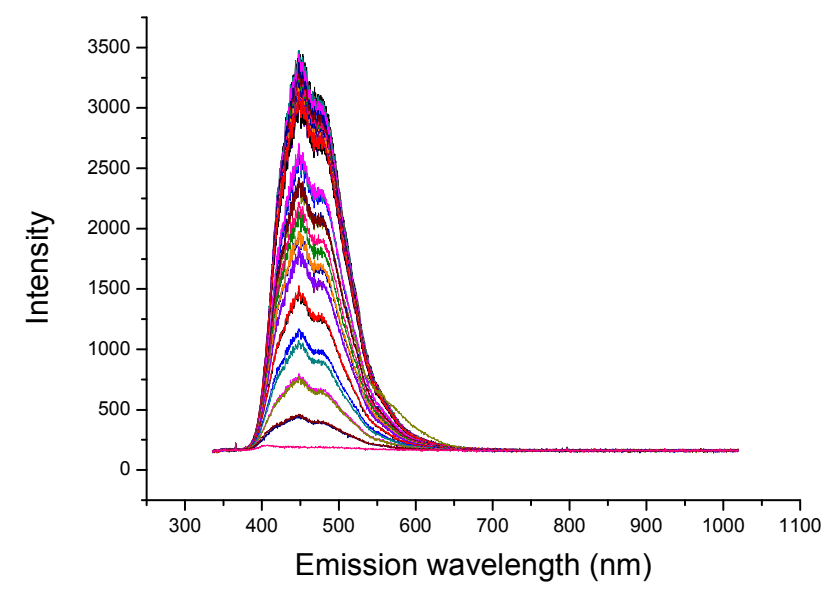

Figure 4. Fluorescence spectra for mixture of turpentine in diesel (0-100\%)

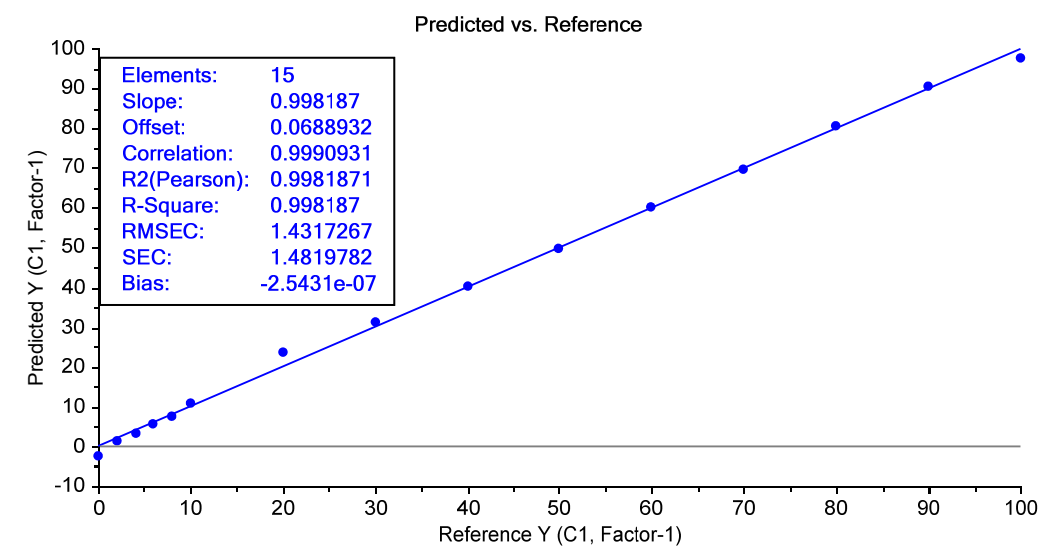

Figure 5. PLS model de mixtures of turpentine added to diesel

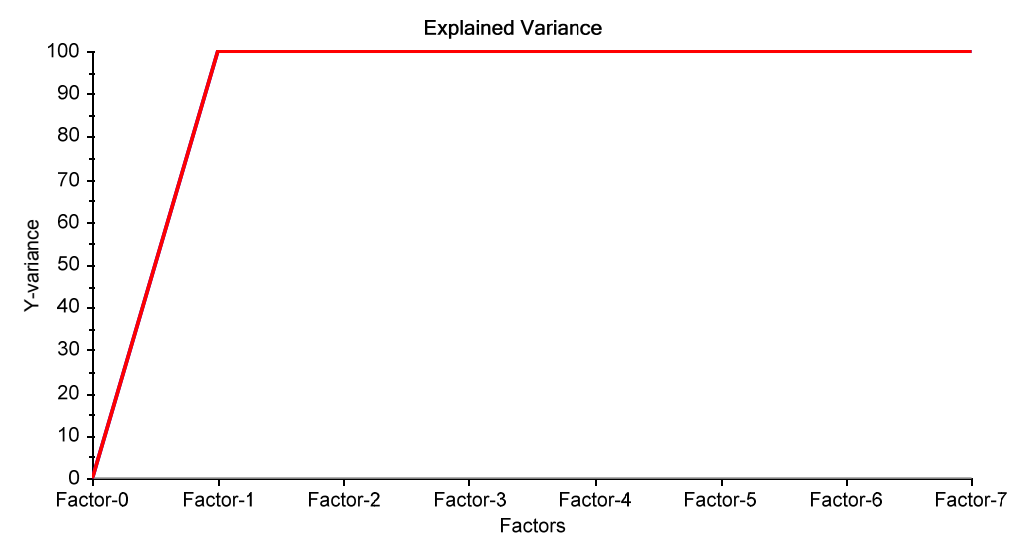

Figure 6. Explained variance of the PLS model de mixtures of turpentine added to diesel 
Figures 7 and 8 present respectively fluorescence spectra and PLS for the mixtures of residual oil from fried foods in diesel. The coefficient of correlation of the curve presented near to $1(0.9991)$ and $\mathrm{R}^{2}$ of 0.9938 indicated the strength of the association of the two variables and the efficiency of the PLS to carry out the predictions. For mixtures of residual oil from fried foods added to diesel only two latent variables were shown to predict almost $100 \%$ of the total variance, $86 \%$ for the first and $13 \%$ for the second latent variable) (Figure 9). Therefore, the model was proved useful to predict changes in concentration of residual oil from fried foods added to diesel based on the fluorescence spectral variance.

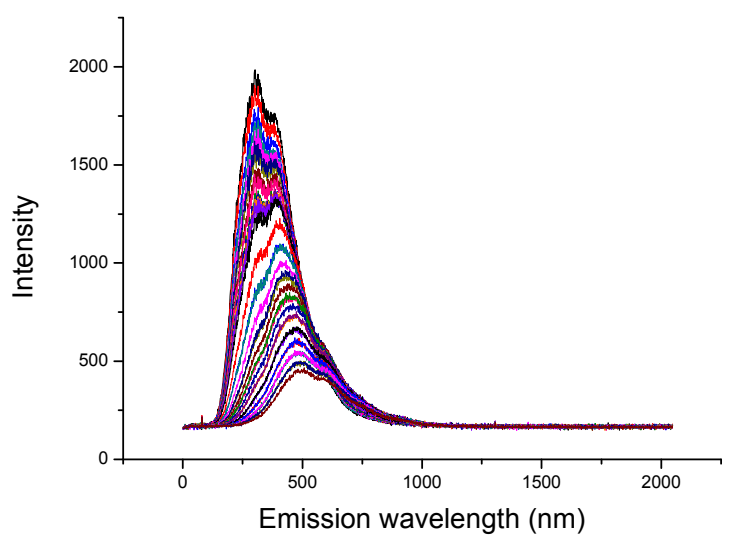

Figure 7. Fluorescence spectra for mixture of residual oil from fried foods in diesel (0-100\%)

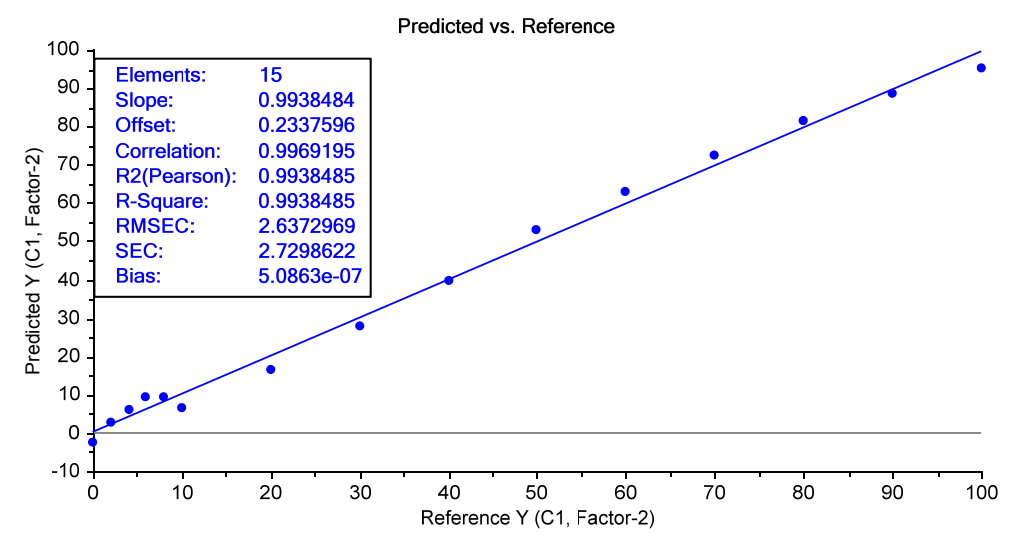

Figure 8. PLS model de mixtures of residual oil from fried foods added to diesel

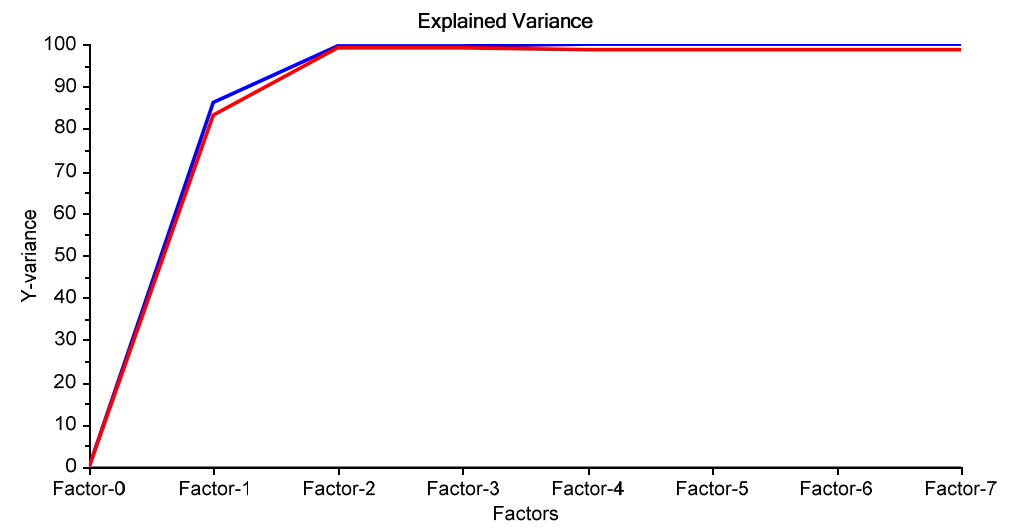

Figure 9. Explained variance of the PLS model de mixtures of residual oil from fried foods added to diesel 


\subsection{Validation of the PLS Models}

The results of the calibration were used to estimate the concentrations from samples that were not used in the PLS models. The concentration values of the mixtures of diesel with adulterant (kerosene, turpentine or residual oil from fried foods) used in this validation procedure are show in the Table 2. The mixtures of each adulterant added to diesel were analyzed by LED values. Table 2 also shows the values of the concentrations predicted by the PLS models. For mixtures of turpentine in diesel and residual oil in diesel some anomalous samples determined by the software Unscrambler were excluded of the data set of validation.

Table 2. Concentration values of the mixtures of diesel with adulterant (kerosene, turpentine or residual oil from fried foods) used in validation procedure

\begin{tabular}{cccccc}
\hline \multicolumn{2}{c}{ Kerosene } & \multicolumn{2}{c}{ Turpetine } & \multicolumn{2}{c}{ Residual oil from fried foods } \\
\hline $\begin{array}{c}\text { Reference } \\
\text { concentration }\end{array}$ & $\begin{array}{c}\text { Predicted } \\
\text { concentration }\end{array}$ & $\begin{array}{c}\text { Reference } \\
\text { concentration }\end{array}$ & $\begin{array}{c}\text { Predicted } \\
\text { concentration }\end{array}$ & $\begin{array}{c}\text { Reference } \\
\text { concentration }\end{array}$ & $\begin{array}{c}\text { Predicted } \\
\text { concentration }\end{array}$ \\
\hline 4 & 4.447487 & 4 & 2.275425 & 4 & 4.882298 \\
$\mathbf{( \% )}$ & $\mathbf{( \% )}$ & 6 & 6.629976 & 8 & 7.487326 \\
$\mathbf{( \% )}$ & 7.13217 & 7 & 6.524025 & 9 & 8.7575 \\
7 & 6.610565 & 9 & 8.505703 & 20 & 16.39527 \\
8 & 6.716967 & 10 & 10.05119 & 25 & 22.19561 \\
9 & 10.24765 & 8.880089 & 35 & 32.90361 \\
10 & 11.11698 & 20 & 23.57909 & 40 & 38.77464 \\
15 & 15.35029 & 30 & 31.68184 & 45 & 45.54182 \\
20 & 19.18914 & 35 & 37.47498 & 50 & 52.12151 \\
25 & 26.73995 & 45 & 44.97174 & 60 & 62.11739 \\
30 & 29.39688 & 50 & 49.81948 & 70 & 72.27793 \\
35 & 33.88729 & 60 & 59.53387 & 80 & 80.72224 \\
40 & 40.12534 & 70 & 72.39371 & 90 & 88.56984 \\
45 & 43.4324 & 80 & 81.3277 & & \\
50 & 50.78994 & 90 & 90.1039 & & \\
60 & 56.99543 & & & & \\
70 & 69.38918 & & & & \\
80 & 79.42979 & & & & \\
90 & 90.06597 & & & & \\
\hline
\end{tabular}

\section{Conclusion}

The association of spectrofluorimetry and PLS was suitable for predict the concentration of adulterants (kerosene, turpentine or residual oil from fried foods) added to diesel

The advantages of the fluorescence spectroscopy inducted by LED, such as simplicity, quickness, low-cost suggest this method as a analytical procedure for the evaluation of the concentration of adulterants previously identified qualitatively in diesel.

The $R^{2}$ near to 1 for mixtures of diesel with kerosene, turpentine and residual oil from fried foods indicated the accuracy of the models to predict concentrations values of this adulterants added to diesel.

\section{Acknowledgements}

We acknowledge the CNPq, FAPESB and CAPES for technological scholarships and financial support.

\section{References}

Brandão, L. F. P., Braga, J. W. B., \& Suarez, P. A. Z. (2012). Determination of vegetable oils and fats adulterants 
in diesel oil by high performance liquid chromatography and multivariate methods. Journal of Chromatography A, 1225, 150-157. http://dx.doi.org/10.1016/j.chroma.2011.12.076

Corgozinho, C. N. C., Pasa, V. M. D., \& Barbeira, P. J. S. (2008). Determination of residual oil in diesel oil by spectrofluorimetric and chemometric analysis. Talanta, 76, 479-484. http://dx.doi.org/10.1016/j.talanta.2008.03.003

Gaydou, V., Kister, J., \& Dupuy. N. (2011). Evaluation of multiblock NIR/MIR PLS predictive models to detect adulteration of diesel/biodiesel blends by vegetal oil. Chemom Intell Lab Syst, 106, 190-197. http://dx.doi.org/ 10.1016/j.chemolab.2010.05.002

Meira, M., Quintella, C. M., Ferrer, T. M., Silva, H. R. G., Guimarães, A. K., Santos, M. A., ... Pepe, I. M. (2011). Identification of adulteration of biofuel by addition of residual oil instead of biodiesel to the diesel by total spectrofluorimetry and principal component analysis. Quim Nova, 34, 621-624. http://dx.doi.org/10.1590/S0100-40422011000400013

Oliveira, F. C. C., Brandão, C. R. R., Ramalho, H. F., Costa, L. A. F., Suarez, P. A. Z., \& Rubim, J. C. (2007). Adulteration of diesel/biodiesel blends by vegetable oil as determined by Fourier transform (FT) near infrared spectrometry and FT-Raman spectroscopy. Anal. Chim. Acta., 587, 194-199. http://dx.doi.org/10.1016/j.aca.2007.01.045

Patra, D., \& Mishra, A. K. (2002). Study of diesel fuel contamination by excitation emission matrix spectral subtraction fluorescence. Anal. Chim. Acta, 454, 209-215. http://dx.doi.org/10.1016/S0003-2670(01)01568-9

Pontes, M. J. C., Pereira, C. F., Pimentel, M. F., Vasconcelos, F. V. C., \& Silva, A. G. B. (2011). Screening analysis to detect adulteration in diesel/biodiesel blends using near infrared spectrometry and multivariate classification. Talanta, 85, 2159-2165. http://dx.doi.org/10.1016/j.talanta.2011.07.064

Quintella, C. M, Guimarães, A. K., Musse, A. P., \& Patent, B. R. (2009). PI000022080730742-1.

Quintella, C. M., Meira, M., Silva, H. R. G., Guimarães, A. K., Ferrer, T. M., Santos, M. A., ... Pepe, I. M. (2011). Patent BR PI 011110000662.

Roy, S. (1999). Fiber optic sensor for determining adulteration of petrol and diesel by kerosene. Sensors Actuat B: Chem. Actuat. B: Chemical, 55, 212-216. http://dx.doi.org/10.1016/S0925-4005(99)00171-9

Souza, L. M., Mitsutake, H., Gontijo, L. C., \& Borges, N. W. (2014). Quantification of residual automotive lubricant oil as an adulterant in Brazilian S-10 diesel using MIR spectroscopy and PLS. Fuel, 15, 257-262. http://dx.doi.org/10.1016/j.fuel.2014.03.051

Vasconcelos, F. V. C., Souza, Jr., P. F. B., Pimentel, M. F., Pontes, M. J. C., \& Pereira, C. F. (2012). Using near-infrared overtone regions to determine biodiesel content and adulteration of diesel/biodiesel blends with vegetable oils. Anal. Chim. Acta, 716, 101-107. http://dx.doi.org/10.1016/j.aca.2011.12.027

Young, I. T., Garini, Y., Dietrich, H. R. C., van Oel, W., \& Liqui Lung, G. (2004). LEDs for fluorescence microscopy. Proc. of SPIE, 5324, 208-215. http://dx.doi.org/10.1117/12.525932

\section{Copyrights}

Copyright for this article is retained by the author(s), with first publication rights granted to the journal.

This is an open-access article distributed under the terms and conditions of the Creative Commons Attribution license (http://creativecommons.org/licenses/by/3.0/). 